Tetraheđron Letters, Vol.26, No.52,pp 6419-6422,1985

Printed in Great Britain
$0040-4039 / 85 \$ 3.00+.00$

01985 Pergamon Press Ltd.

\title{
A NOVEL AND EFEICIENT SYNTHESIS OF THE NATURALLY OCCURRING NUCLEOSIDE DORIDOSINE ${ }^{l}$
}

\section{JI-WANG CHERN AND LEROY B. TOWNSEND*}

Department of Medicinal Chemistry, College of Pharmacy and Department of Chemistry. The University of Michigan,

Ann Arbor. MI 48109-1065

Abstract: 1-Methylisoguanosine was synthesized by a one-pot reaction involving a condensation of 5-amino-1-( $\beta$-D-ribofuranosy 1$)$ imidazole-4-carboxamide ( 1 ) with methyl isothiocyanate, treatment of the resulting thiourea derivative with DCC furnished 5-(3-methyl-1-ureido)-1-(B-Dribofuranosyl) imidazole-4-carbonitrile (4) which was then annulated with ethanolic ammonia to furnish doridosine in a $68 \%$ yield from $\underline{1}$.

1-Methylisoguanosine (5, doridosine, 6-amino-1-methy1-9-B-D-ribofuranosylpurin-2-one) was recently isolated from three different marine animals by three independent laboratories. 2-4 This compound has been shown to possess potent muscle-relaxant activity, as well as a lowering of blood pressure and antiinflammatory activity. ${ }^{5-8}$ Doridosine and a variety of doridosine analogs have been synthesized and studied ${ }^{9,10}$ because of the biological activity observed for doridosine. Doridosine, per se, has been synthesized ${ }^{3,9,11}$ by a direct methylation of isoguanosine with methyl iodide or by the cyclization of an appropriate imidazole nucleoside. The first method has furnished a mixture of 1-methylisoguanosine and 2-methoxyadenosine, both of which were obtained in relatively poor yield. ${ }^{3}$ The second method involved a conversion of the commercially available 5-amino-1-(B-D-ribofuranosyl)imidazole-4-carboxamide (AICA-riboside) into its tri-o-acetyl derivative, which was then treated with phosphorus oxychloride to obtain 5-amino-4-cyano-1-(2,3,5-tri-o-acety 1-B-D-ribofuranosyl)imidazole (tri-o-acetyl derivative of AICN-riboside). However, this nitrlle derivative was contaminated with some highly colored impurities and needed extensive column chromatography in order to obtain pure material. Compound $\underline{5}$ was then obtained by a reaction of the protected AICN-riboside with methyl isocyanate, followed by cyclization and deprotection with methanolic ammonia. The second method gave a $39 \%$ yield of 5 from AICA-riboside.

As part of our continuing study on the development of new methodology for the formation of heterocyclic compounds, we have recently reported ${ }^{12}$ a facile and interesting procedure for the synthesis of 5-(3-methoxycarbonyl-1-ureido)-1-(B-D-ribofuranosyl)imidazole-4-carbonitrile

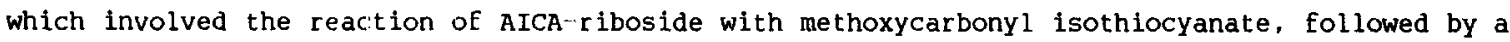
cyclodesulfurization of the resulting thioureido derivative with dicyclohexylcarbodiimide. Subsequent studies $\left({ }^{18} \mathrm{o}\right.$ labeling) in our laboratory ${ }^{13}$ have provided strong support for a mechanism which involves the formation of a [1,3]oxazine intermediate with the carboxamide oxygen ultimately becoming part of the ureido group. Our successful synthesis of this AICNriboside derivative Erom AICA-riboside under such mild conditions suggested that this approach might provide a new, novel and more efficient synthetic route for the preparation of doridosine and some structurally related derivatives.

A retro synthetic evaluation using this approach indicated that an initial condensation of 
the commercially avatlable AICA-ribostde and methyl 1sothlocyanate should provide 5-(3-methyl-1 thioureido)-1-(B-D-ribofuranosyl) Imidazole-4-carboxamide (2). A subsequent cyclodesulfurization of compound $\underline{2}$ with DCC should provide 5-(3-methyl-1-ureido)-1 (B- $\underline{\text { - }}$ ibofuranosy1) imidazole-4-carbonitrile ( 4 ) which could then be annulated to provide the desired nucleoside 5 .

A solution of AICA-riboside (1, $2.35 \mathrm{~g}, 9.1$ mmoles) and methyl isothiocyanate (5 ml, 73 mmoles) in $\underline{\mathrm{N}}, \underline{\mathrm{N}}-$ dimethylformamide $(20 \mathrm{~mL})$ was heated at $80^{\circ} \mathrm{C}$ for 12 hours. The solvent was then removed to afford an oil which was dissolved in methanol (10 mL). The white solid which was formed by the addition of ether $(100 \mathrm{~mL})$ was collected by filtration, and washed with ether $(20$ mL). This solid was determined to be compound 2 by TLC and a ${ }^{1}$ H-NMR spectrum. ${ }^{14}$<smiles>[R]n1cnc(C(N)=O)c1N</smiles><smiles>[R]C[C@H]1O[C@H](C)[C@@H](O)[C@H]1O</smiles>

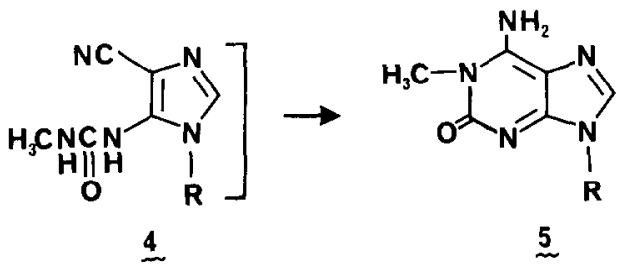

\section{Scheme I}

This solid was found to be very hygroscopic, therefore, the crude product was imaediately dissolved in DMF ( $50 \mathrm{~mL})$, dicyclohexylcarbodiimide $(5.6 \mathrm{gm}, 27.3 \mathrm{mmoles})$ was added to the resulting solution and the mixture stirred at room temperature for 24 hours. The solvent was then removed to afford an oil which was dissolved in a mixture of methanol and chloroform $(10 \mathrm{~mL}$, v/v, 2:8) with flash chromatography being used to remove the fast-moving band of dicyclohexylthiourea and DCC. The column was then eluted with methanol to obtain a fraction 
containing the nucleoside material, as determined by TLC, and the solvent renoved to obtain an oil. Ethanol ( $100 \mathrm{~mL})$ and $58 \%$ ammonium hydroxide $(20 \mathrm{~mL})$ was added to this oil and the mixture was stirred at room temperature. After $30 \mathrm{~min} .$, a white solid separated, but the reaction mixture was allowed to stir at room temperature for an additional 12 hours. The solid was then collected by filtration to give $1.3 \mathrm{~g}$ of pure doridosine ( $\underline{5}$ ). This synthetic sample was found to be identical (IR, UV, ${ }_{\mathrm{H}-\mathrm{MMR}}$ and MS) to the naturally occurring nucleoside doridosine based on a comparison of data for $\underline{5}$ and the reported ${ }^{3}$ data as follows: M.p. $270-271^{\circ} \mathrm{C}$ (1it. ${ }^{11} 266-267^{\circ} \mathrm{C}$ ); $\operatorname{IR}(\mathrm{KBr}): 3500,3455,3200,3100,1690,1640,1600,1580,1525,1430$, 1400, 1200, 1080, 1050, 1020, $850 \mathrm{~cm}^{-1}$; UV $\lambda_{\max } \mathrm{nm}\left(\varepsilon \times 10^{4}\right):($ (МеOH) $250(0.84), 299$ (1.15); ( $\mathrm{pH} \mathrm{1)} 234(0.7), 283(1.37)$; mass spectrum, $\mathrm{m} / \mathrm{z} 298\left(\mathrm{M}^{+}+\mathrm{H}\right), 208(\mathrm{~B}+44), 194(\mathrm{~B}+$

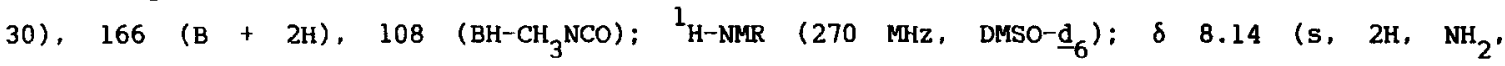
$\mathrm{D}_{2} \mathrm{O}$ exchangeable). $7.90(\mathrm{~s}, 1 \mathrm{H}, \mathrm{H}-8), 5.70\left(\mathrm{~g}, 1 \mathrm{H}, \mathrm{H}^{-5} 5^{\mathrm{O}} \mathrm{OH}, \mathrm{D}_{2} \mathrm{O}\right.$ exchangeable $), 5.60(\mathrm{~d}, 1 \mathrm{H}$, $\left.\mathrm{H}^{-1}, \mathrm{~J}=6.4 \mathrm{~Hz}\right), 5.33\left(\mathrm{~d}, 1 \mathrm{H}, \mathrm{H}-2^{\prime} \mathrm{OH}, \mathrm{J}=6.4 \mathrm{~Hz}, \mathrm{D}_{2} \mathrm{O}\right.$ exchangeable $), 5.07$ (d, $1 \mathrm{H}, \mathrm{H}^{\prime} 3^{\prime} \mathrm{OH}$, $J=4.3 \mathrm{~Hz}, \mathrm{D}_{2} \mathrm{O}$ exchangeable), $4.53\left(\mathrm{q}, 1 \mathrm{H}, \mathrm{H}^{-2} \mathbf{2}^{\prime}\right), 4.06\left(\mathrm{q}, 1 \mathrm{H}, \mathrm{H}^{-3} 3^{\prime}\right), 3.90\left(\mathrm{q}, 1 \mathrm{H}, \mathrm{H}^{-4^{\prime}}\right)$, 3.63-3.44 (m, $\left.2 \mathrm{H}, \mathrm{H}^{\prime}-5\right), 3.59\left(\mathrm{~s}, 3 \mathrm{H}, \mathrm{CH}_{3}\right)$. High resolution mass spectrometry demonstrated that the base peak $\mathrm{C}_{6} \mathrm{H}_{8} \mathrm{~N}_{5} \mathrm{O}(\mathrm{m} / \mathrm{z}$ 166) corresponds to a methylisoguanine fragment. We observed the loss of a $N(1)-C(2)$ unit from the base peak ( $\mathrm{m} / \mathrm{z} 166)$, which is particularly relevant to the structural determination of $\underline{5}$. This loss was used to establish the position of methylation in the isoguanosine series ${ }^{3,5}$. The filtrate was evaporated in vacuo to afford an oil, water $(10 \mathrm{~mL})$ was added to the oil, and the mixture allowed to stand at room temperature for 24 hours. The solid was collected by filtration to give an additional $0.5 \mathrm{~g}$ of pure compound $\underline{5}$. The total comblned yield of compound $\underline{5}$ was $1.8 \mathrm{~g}(68 \%)$. This yield was obtained without any attempt to optimize the reaction conditions.

It would appear that this methodology may provide a new and novel general route for the preparation of various doridosine analogs containing an amino-N-alkylpyrimidinone moiety via a simple variation of the isothiocyanate and the ortho amino-carboxamide heterocycles used in the initial condensation. The scope of this methodology is under investigation in our laboratory.

Acknowledgment: This investigation was supported by PHS Grant CA 28381 awarded by the National Cancer Institute, DHHS. The authors would also like to acknowledge the NIH Biomedical Research Support (RR 01437) for funds toward the purchase of the IBMNP-270SY NMR Spectrometer and thank Ms Deanna Vansickle for assistance in the preparation of this manuscript.

\section{References:}

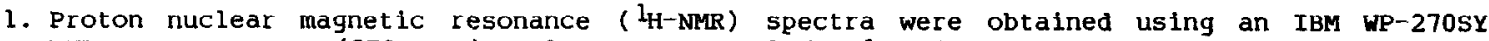
NMR spectrometer $(270 \mathrm{MHz})$ and are reported in $\delta$ units with tetramethylsilane (Me $\mathrm{Si}^{\mathrm{S}}$ ) as the internal standard. Coupling constants $(J)$ are given in hertz; $s=s i n g l e t$, $d=$ doublet, $t=t r i p l e t, q=$ quartet. Melting points are uncorrected and were determined on a Thomas-Hoover melting point apparatus. UV spectra were recorded on a Hewlett Packard UV 8450 spectrometer. IR spectra were recorded on a Perkin-Elmer 281 spectrophotometer. Mass spectral data were obtained on a Finnigan Model $4023 \mathrm{GC} / \mathrm{MS}$ using electron ionization. Thin 
layer chromatography (TLC) was performed with Analtech silica gel GHLF TLC plates (250 microns).

2. R. J. Quinn, R. P. Gregson, A. F. Cook, and R. T. Bartlett, Tetrahedron Lett. 21 . 567 (1980).

3. A. F. Cook, R. T. Bartlett, R. P. Gregson, and R. J. Quinn, I. Orq. Chem. 45,4020 (1980).

4. K. Grozinger, K. R. Freter, P. Farina, and A. Gladczuk, Eur. J. Med. Chem.-Chim. Ther. 18, 221 (1983).

5. F. A. Fuhrman, G. J. Fuhrman, Y. H. Kim, L. A. Pavelka, and H. S. Mosher, Science, 207, 193 (1980).

6. J. A. Baird-Lambert, J. F. Marwood, L. P. Davies, and K. M. Taylor, Life Sci., 26, 1069 (1980).

7. L. P. Davies, K. M. Taylor, R. P. Gregson, and R. J. Quinn, Life Sci., 26, 1079 (1980).

8. R. T. Bartlett, A. F. Cook, M. S. Poonian, and K. M. Taylor, Life Sci., 26, 1089 (1980).

9. R. T. Bartlett, A. F. Cook, M. J. Holman, W. W. McComas, E. F. Nowoswait, M. S. Poonian, J. A. Balrd-Lambert, B. A. Baldo, and J. F. Marwood, J. Med. Chem., 24, 947 (1981).

10. Y. H. Kim, S. J. Jee, and H. S. Mosher, Heterocycles, 23, 21 (1985).

11. A. F. Cook, and R. T. Bartlett, in "Nucleic Acld Chemistry, Improved and New Synthetic Procedures, Methods, and Techniques", L. B. Townsend and'R. S. Tipson, Eds.; Wiley: New York, 1985, Vol. 3, p 140.

12. J.-W. Chern, M. P. Groziak, and L. B. Townsend, J. Heterocyclic Chem. (in press).

13. M. P. Groziak, J.-W. Chern, and L. B. Townsend, J. Org. Chem. (submitted for publication).

14. It is of some interest that a bis-(methylcarbamoyl) adduct was obtained ${ }^{3}$ from a condensation of 5-amino-1-(2,3,5-tri-0-acetyl-B-D-ribofuranosyl)imidazole-4-carbonitrile with excess methyl isocyanate. However, the $1_{\mathrm{H}-\mathrm{NMR}}$ spectrum of compound $\underline{2}$ revealed a doublet centered at $\delta 2.88$ which supported the presence of only a single $\mathrm{N}-\mathrm{CH}_{3}$ group . on the basis of this spectrum, the structure of compound 2 was assigned as the mono-N-methyl-thiocarbamoyl adduct instead of the bis-( - -methylthiocarbamoyl) derivative. $\mathrm{L}_{\mathrm{H}-\mathrm{NMR}}$ (270 MHz, DMSO- $\left.\underline{\mathrm{d}}_{6}\right)$ spectrum of compound $\underline{2}: \delta 8.96$ ( $\left.\mathrm{s}, 1 \mathrm{H}, \mathrm{NH}\right), 7.95$ ( $\left.\mathrm{s}, 1 \mathrm{H},=\mathrm{C}-\mathrm{H}\right), 7.87$ (br $\mathrm{s}$, $1 \mathrm{H}, \mathrm{NH}), 7.20\left(\mathrm{~s}, 1 \mathrm{H}, \mathrm{NH}_{2 \mathrm{a}}\right), 7.03\left(\mathrm{~s}, 1 \mathrm{H}, \mathrm{NH}_{2 b}\right), 5.46\left(\mathrm{~d}, \mathrm{lH}, \mathrm{H}-\mathrm{I}^{\prime}, \mathrm{J}=3.3 \mathrm{~Hz}\right), 5.23$ (d, $\left.1 \mathrm{H}, \mathrm{H}-2^{\prime} \mathrm{OH}, \mathrm{J}=4.9 \mathrm{~Hz}\right), 5.09\left(\mathrm{~d}, 1 \mathrm{H}, \mathrm{H}^{-3} 3^{\prime} \mathrm{OH}, \mathrm{J}=5.3 \mathrm{~Hz}\right), 5.01\left(\mathrm{t}, 1 \mathrm{H}, \mathrm{H}^{-5} \mathrm{OH}\right), 4.13$ (q, $\left.1 \mathrm{H}, \mathrm{H}^{-2^{\prime}}\right), 4.05\left(\mathrm{q}, 1 \mathrm{H}, \mathrm{H}^{-} 3^{\prime}\right), 3.82\left(\mathrm{q}, 1 \mathrm{H}, \mathrm{H}^{-4} 4^{\prime}\right), 3.57-3.51\left(\mathrm{~m}, 2 \mathrm{H}, \mathrm{H}^{-} 5^{\prime}\right), 2.88(\mathrm{~d}$, $\left.3 \mathrm{H}, \mathrm{CH}_{3}\right)$.

(Received in USA 7 August 1985) 